\title{
Can re-distributed manufacturing and digital intelligence enable a regenerative economy? An integrative literature review \\ Mariale Moreno, Fiona Charnley
}

Cranfield University, Centre for Creative and Competitive Design. Building 82. School of Environment, Energy and AgriFood. Bedfordshire, MK43 0AL. UK. m.moreno, f.j.charnleyecranfield.ac.uk

\begin{abstract}
This paper uses an integrative literature review to explore the concept of re-distributed manufacturing and the opportunities to deliver more regenerative and resilient systems of production and consumption through the application of circular innovation. The study identified multiple similarities between the drivers of re-distributed and circular models of production and consumption that could be fostered by the use of digital intelligence. A set of criteria for redistributed manufacturing and circular innovation were developed and used to identify 33 existing case studies of consumer goods production. Case study analysis resulted in the identification of three types of re-distributed manufacturing that integrated characteristics of circular innovation. The paper concludes by describing some of the future research challenges in the transition towards re-distributed and circular models of production.
\end{abstract}

Keywords. Re-distributed Manufacturing (RdM), de-centralisation, circular economy, digital intelligence, consumer goods.

\section{Introduction}

The linear production of the consumer goods industry, worth approximately USD3.2 trillion, has remained largely unchanged and places emphasis on mass manufacture through multi-national corporations and globally dispersed supply chains with $80 \%$ of materials ultimately ending up in landfills. Consumer goods production, has created a void between the manufacturer and end user, limiting the opportunity for personalisation, up scaling of local enterprise and the development of user-driven products that are tuned to the requirements of local markets. It is proposed that Re-distributed Manufacturing ( $\mathrm{RdM}$ ) enables a connected, localised and inclusive model of consumer goods production and consumption that is driven by the exponential growth and embedded value of big data.

The EPSRC-ESRC ${ }^{1}$ funded Network in Re-distributed Manufacturing, Consumer Goods and Big Data (RECODE) has been created to explore the opportunities and challenges to build a research agenda associated with the application of big data in the

\footnotetext{
${ }^{1}$ EPSRC and ESRC are part of the UK Research Council funding bodies on Engineering and Physical Sciences Research Council and Economic and Social Research Council respectively.
} 
transition towards a re-distributed manufacturing model for consumer goods. As part of this network a feasibility study on circular innovation and RdM has been conducted to explore the requirements of $\mathrm{RdM}$ enabled by big data to deliver de-centralised and circular models of consumer goods production and consumption.

The concepts of circular innovation and RdM are relatively new. However, there has been an increasing interest for the last ten years from different scholars and research consultancies $[1,2,3,4,5,6,7,8,9]$ in the topic of circular innovation, and its implications mainly in China, and most recently in the developed world pronominally in Europe. The interest in RdM is even more recent and there are still different descriptions and interpretations about the concept $[10,11,12,13,14,15]$.

For the purpose of this paper, circular innovation and circular economy will be used in parallel to describe an "industrial economy that is restorative by intention and design where transformational changes through innovations are applied to decouple human wellbeing form resource use and environmental impact” [6, p7]. In addition, RdM will be defined as "the shift from centralized to decentralized manufacture with the aim to create a more resilient and connected system taking advantage of digital intelligence and newly emerging technologies, to provide agile, user driven approach that will allow for personalisation and customisation of products to local markets'.

To investigate the relationship of these two concepts, this paper aims to explore, through an integrative literature review, the concept of re-distributed manufacturing and the opportunities to deliver more regenerative and resilient systems of production and consumption through the application of circular innovation. The paper starts with a review of the fundamental drivers of circular economy and RdM from which criteria, that describe the similarities and differences of both models, are identified. These criteria were then used to analyse 33 case studies of consumer goods production, which resulted in the definition of three models of $\mathrm{RdM}$ with circular innovation characteristics. The paper concludes by describing some of the future research challenges in the transition towards re-distributed and circular models of production.

\section{Fundamental drivers of circular economy and RdM}

According to Lacy and Rutqvist [9], the three fundamental drivers of the circular economy are: resource constraints, technological development and socio-economic opportunities. These drivers are not so far off from the drivers that could enable the decentralisation of manufacturing. Although, $\mathrm{RdM}$ is not primarily driven by a need to address sustainability issues, it is predicted that the introduction of digital intelligence and connected objects would potentially reduce resource use and will enable circular systems [16]. Emerging technologies such as automation and robotics, big data analytics, the Internet of Things (IoT), additive manufacturing, cloud computing, mobile technologies, social networks, and modular design amongst others support the transition towards a more connected decentralised manufacturing systems [14]. A clear strategic vision of the capabilities of digital intelligence to enable $\mathrm{RdM}$ is the German vision of Industry 4.0. INDUSTRIE 4.0 is described as the "paradigm shift 
from 'centralised' to 'decentralised' production made possible by technological advances which constitute a reversal of conventional production process logic" [17, p5]. It is foreseeing that Industry 4.0, will transform the design, manufacture, operation, and service of products as well as the way consumption is done due to the elevate mass customisation that will be enabled [18].

To enable RdM in the consumer goods sector there is clear evidence of the opportunities that could be enabled by the application of digital intelligence. To relate these opportunities to the circular economy is important to analyse the environmental and socio-economic benefits that their application in the consumer goods sector could bring. In terms of environmental benefits, digital intelligence will support new business models to effectively manage resources within markets, ensure waste is eliminated and monetized [9], and support selling products as services which will enable keeping products in longer use to minimise waste and resources [3,9]. In addition, if technologies such as additive manufacturing are intentionally designed to reduce the amount of materials required in production, it could contribute to reduce the use of resources and waste [19]. Emissions from transportation could be also minimised by increased flexibility and greater control provided by the use of digital intelligence. Shifting to regional and localised manufacturing increases the potential to minimise transport and internalise material flows by being closer to the consumer [19].

To better understand the socio-economic benefits, it would require an understanding of where real value could be created by addressing a set of system issues, and enabling new business models for the consumer goods sector [20]. For example, the use of digital intelligence can improve productivity and production efficiency. It is predicted that Industry 4.0 will be embraced by more companies, boosting German productivity by $€ 90$ billion to $€ 150$ billion in the next five to ten years [17]. In addition, it is evident that companies are constantly constrained by risks resulting from climate change, currency fluctuation and resource security affecting global supply chains. Thus, digital intelligence can be useful to run more resource-productive supply chains by optimising operations, setting in place an optimised inventory, and predicting maintenance [20]. Take for example new technologies that allow trace and return systems. These systems are enabled by digital and physical technologies that allow products to be traced and transferred from end users to the manufacturer or a third party, keeping track and control of assets. By using real time data, it would be more cost-effective for companies to monitor, predict and prevent breakdowns of products and at the same time enable collection for service repair, recover, reuse, or refurbish [20]. With advanced recycling technologies, trace and return systems will also drive new opportunities to collect, process, and reuse materials, leading to more interconnected markets in which outputs are used across industries as inputs [9].

Digital intelligence will also create added value through high customisation of products and services. Mass customisation is foreseen as a dominant model for satisfying varying consumer needs [18]. This will not just drive revenue growth as consumers would be prepared to pay a premium up to $10 \%$ for personalised goods, but also will enable closer relationships between companies and the communities they operate within [10]. Consumers would gain more value through convenience, time saving, 
and more attractive customised promotions [18]. High customisation will also provide a significant breakthrough in health and wellbeing. Digital intelligence is already being used to monitor and treat illness, and it is foreseeing that it will improve wellness by using data generated by wearable technologies to track and modify diet and exercise routines. It is predicted that these technologies will cut the costs of chronic disease treatment by as much as $50 \%$ [18].

The application of digital intelligence on the consumer goods sector will increase the demand for employees with certain skills in software development and IT technologies [18]. However, the decentralisation of manufacturing might not lead to the creation of significant numbers of new jobs as greater automation will displace some of the often low skilled labourers $[18,19]$. As such, greater education and training to adopt good analytical capabilities as well as software development capabilities would need to be a feasible option for many [21]. Thus a significant shift in the skill profile is required to deliver significant value [18].

Consumer goods companies such as Unilever ${ }^{2}, \mathrm{Coca}_{\mathrm{Cola}}{ }^{3}$ and L'Oreal ${ }^{4}$ are already seeing the benefits that implementing digital intelligence can bring into their processes and business model. For example, these companies have established open innovation portals to outsource ideas for new innovations. Whilst the opportunities that digital intelligence can bring exist, the question still persists if meeting demand on a smaller scale, by at the same time delivering more regenerative and resilient systems of production and consumption, will be feasible for the consumer goods sector. To answer this question, it was necessary to define a series of criteria that define RdM and circular innovation in order to analyse case studies in this sector. This analysis aimed to have a better understanding of the feasibility of decentralising the consumer good sector whilst at the same time enabling circular innovation.

\section{Criteria Definition and Case study analysis}

The case study analysis used secondary data to examine 33 case studies of existing local, regional and global business models within the consumer goods sector. To choose the case studies they had to demonstrate: 1) the use of digital intelligence, 2) demonstrate de-centralised, re-distributed and circular production and consumption, and 3) had to be business to consumer in which the final user is an individual or household. The case studies analysed, referred to in figure 1, belong to different subsectors of the consumer goods industry according to Euromonitor International Database. ${ }^{5}$ The sample of case studies was sourced from online resources such as reports, news, blogs, and websites, using key words such as 'distributed manufacturing', 'circular economy', 'personalisation', ‘customisation', 'localisation', 'Internet of Things', 'Big Data' plus 'case studies' and 'examples.'

\footnotetext{
${ }^{2}$ https://oiportal.yet2.com/

${ }^{3} \mathrm{http}: / /$ us.coca-cola.com/happiness/

${ }^{4} \mathrm{http}: / / \mathrm{www}$.loreal.com/research-and-innovation

${ }^{5} \mathrm{http} / / /$ www.euromonitor.com/
} 
To analyse these case studies, different criteria were identified through the literature that could be used to define RdM and circular innovation. As both fields of research are still in their infancy, the available literature is disjointed, with multiple perspectives. The criteria were therefore developed based on the current review of literature and the most well used definitions of RdM and circular innovation, introduced in section one. Findings from the literature review were thematically analysed and categorised into themes and sub-themes by the researchers. This analysis resulted in five themes and 19 sub-themes to define RdM and four themes and 17 sub-themes to define circular innovation. These themes became the criteria against which to analyse each case study, case by case and are explained in detail in section 3.1 through use of relevant literature.

\subsection{RdM criteria}

The RdM criteria set was classified into Localisation, Customisation, Distributed Ownership, Distributed Knowledge and Distributed Structure.

a. Localisation: $\operatorname{RdM}$ is about decentralising the raw materials and methods of fabrication, so the final product is manufactured very close to the final customer [26]. As such elements of localisation such as regional and urban settings needed to be considered. On-shoring, where the repatriation of production from low cost locations is a continued trend, off-shoring in certain consumer goods subsectors will continue to happen in the short term due to proximity of raw materials and costs $[14,16]$. Thus in the short term, we will see a geographically distributed production system in which will be based on a decentralised production structure with different facilities [12].

b. Customisation: According to Kohtala [10] distributed production brings a range of emerging practices where households can affect what is produced from product personalisation to personal fabrication. In addition, she argues that with the use of digital intelligence, these practices had entered a mainstream of customisation in different forms. Thus, Kohtala [ibid] classifies the distributed production landscape regarding the level of customisation and control over user versus its scale. This classification is: Mass customisation referring to individual mass production for a large market meeting different needs; bespoke fabrication and information, which tailors individual products and services according to users needs; and mass/personal fabrication, which uses open source design platforms to enable the democratisation of design. Customisation is also related to providing wellbeing, fitness and tailored promotions [20].

c. Distributed Ownership: The use of digital intelligence in distributed models of production and consumption are facilitating new business models in which ownership is shifting to access through providing robust products alongside long-term services $[3,14]$. Distributed ownership has been studied by different scholars over the last 20 years under the topic of product service systems (PSS). A predominant scholar in this topic is Tukker [23] in which he classifies PSS into Product Oriented, Use Oriented and Result Oriented. The latter is not considered as a category of distributed ownership as the the production system is completely replaced 
by a service. E.g. BlablaCar ${ }^{6}$ is a ride sharing platform in which drivers share their ride with other users heading to the same direction. In this case the production of 'new' cars are replaced by a service that uses existing cars.

d. Distributed Knowledge: Distributed production needs the adoption of production networks, which are coordinated [24]. Thus distribution and transfer of knowledge will be essential to facilitate RdM [25]. Knowledge is seen in different forms. Open source innovation offers a closer interaction between consumer, designer and producer in which co-creation is busted through shared knowledge [10]. To take advantage of the opportunities that connected manufacturing could bring through the application of cyber-physical-systems known as Industry 4.0, support and knowledge to develop the sufficient skills to be able to use demanding technologies would be essential [26]. Industry 4.0 has the capacity to address the increasing complexity of products and their supply chain, by providing a full integration of information and knowledge between production and planning levels, and further to customers and suppliers [ibid]. Distribution of knowledge can be finally referred to the use of ancient skills such as craft skills and bridging them with digital technologies. For example, Steffen and Gros [27] studied how decentralised production of furniture can benefit from transfer knowledge of craftsmanship production with digitalised production.

e. Distributed Structure: Distributed structure refers to the structural changes needed to facilitate RdM. According to the Foresight Report [14] on the future of manufacturing, de-centralisation of manufacturing processes will need to have an effective use of global capabilities and adaptable logistic systems to achieve an integrated supply chain enabled by the use of digital intelligence. RdM might also disrupt current retail environments. This is continually increasing by shifting from physical retail to online retailing. Localisation and de-centralisation of manufacturing enabled by digital intelligence could enable manufacturers to become the retailer [14] allowing a distributed retailing process.

\subsection{Circular innovation criteria}

The circular innovation criteria were classified according to the 5 Principles of the circular economy [28], which were interpreted as Value Optimisation (Principle 2), Resource Efficiency and Sufficiency (Principle 1 \& 3), Continued Ownership (Principle 4) and Economic Viability (Principle 5).

a. Value Optimisation: According to Stahel [28] the main focus of the circular economy is to increase the optimization of value creation through an intelligent management of all resources including: human labour, skills and experience, health (including minimizing social issues) and healthcare, education and knowledge, culture and cultural heritage, and natural capital (comprising biodiversity and natural resources).

b. Resource Efficiency and Sufficiency: According to Stahel [29] efficiency and sufficiency are metrics to quantify material efficiency and reductions in material consumption and emissions. Efficiency and sufficiency should be achieved in:

\footnotetext{
${ }^{6} \mathrm{https}: / /$ www.blablacar.co.uk
} 
water, energy, embodied energy, Co2e emissions, end of life through recovery and recycling, reduction of transport and virgin materials.

c. Continued Ownership: Stahel [28] argues that continue ownership by selling goods as services or performance could internalise the cost of risk and of waste, and could provide future resource security. Moreno et al., [3] explored longer and intensive use (based on leasing and share use respectively) as circular models for continued ownership. In addition, Lacy and Rutqvist [9] identified product life extension as one of five circular business models based on continued ownership to recapture value of products through reuse, repair, remanufacture and remarketing goods.

d. Economic Viability: A circular economy needs functioning markets [28]. Thus, economic viability is essential. To shift towards a circular economy that is economically viable, companies will need to think about internalising the cost of risk and waste [4], have an intelligent use of human labour and foster regional job creation [28], and developing a value network that is based on supply chain integration [4].

\section{$4 \quad$ Findings}

The case studies were analysed, case-by-case, against the criteria of RdM and circular innovation explained above. Through using secondary data each case study was assessed to understand if they met or not each criterion (Fig. 1) where a criterion was not found to be represented in a case study the field was left blank. The analysis was undertaken by the first author and arbitrated by the second. Once the analysis was complete a workshop was undertaken with a panel of three experts from across the fields of design, consumer goods and digital intelligence, to validate the criteria, selection of case studies and analysis. Figure 1 represents a matrix in which the case studies (vertical axis) were analysed against the RdM and circular innovation criteria (horizontal axis). A circle was used to depict what criteria was met by each case study.

\subsection{Types of RdM}

From this analysis, it became evident that there were several different types of RdM in which circular innovation characteristics were identified. Further analysis of the case studies was undertaken, particularly focusing on: the application of big data, the integration of distributed knowledge between the production and consumption processes, the levels of customisation that can be achieved, the potential to optimise and deliver value whilst at the same time enabling close-loop systems of production and consumption, and the scale of de-centralisation and localisation. From this analysis three types of RdM with circular innovation characteristics were identified (Fig 2) explained below. 


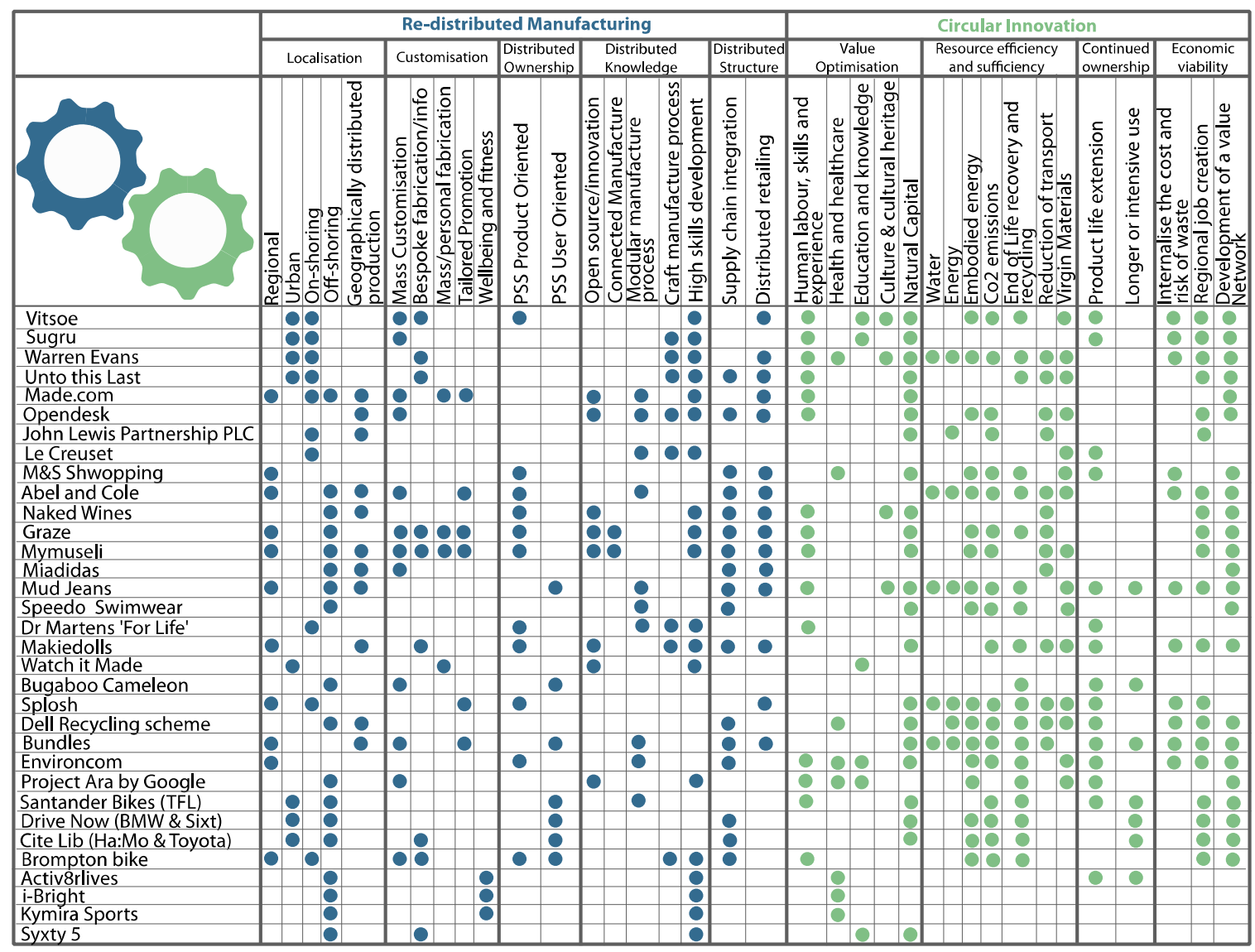

Figure 1 Matrix: Analysis of Case Studies in relation to RdM and Circular Innovation criteria 


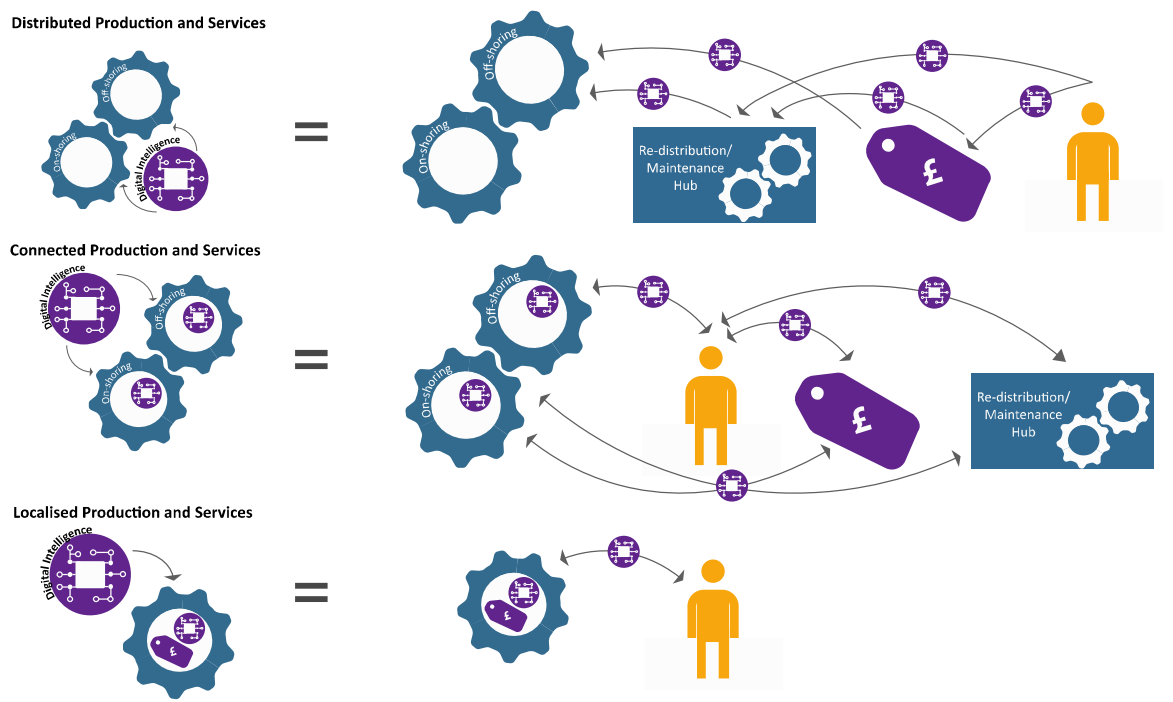

Figure 2 Types of RdM models with circular innovation characteristics

\subsubsection{Distributed Production and Services}

This model represents distributed manufacture that captures big data to monitor the processes of production and consumption. From the three models, this is the one that has the least potential of capturing and delivering value and is most closely linked to our current system, therefore the most cases were identified. This is because most of its capabilities relies on monitoring production and consumption processes. Also, it mainly happens off-shore with some on-shore capabilities of manufacture and remanufacture as well as local capabilities to manage logistical operations. Big data is used to enable mass customisation as it flows just in one direction. Some closed loops of material flows could be captured through monitoring end users. Case studies that were analysed as having these characteristics and represent this model, as depicted in Figure 1, include Sugru, M\&S Shwopping, Slosh and Environcom.

\subsubsection{Connected Production and Services}

This type represents a distributed and digitally connected model. This model can considerably capture high optimisation and delivery of value. This is because, despite manufacture still taking place off-shore and on-shore, it demonstrates a closer proximity to the end user that allows a radical model of consumer goods production, purchase and use. With the use of big data, users can engage in a data-driven open innovation process in which high level of customisation occur as demonstrated in the Opendesk case (Fig 1). It also demonstrates high optimisation of manufacturing processes and logistical operations through the use of digital intelligence such as used by Abel and Cole (Fig 1). In addition, the two-way flows of big data represented in this model allows material flows to be closed easily by the monitor, control and optimisation of resources. 


\subsubsection{Localised Production and Services}

The third type identified represents a localised and highly digitally connected model of $\mathrm{RdM}$ where everything is done on-shore and the retail ecosystem is completely redistributed contributing to the potential of capturing the highest value amongst the three models. This is because users are highly involved in an open be-spoke design and manufacture process, where consumer goods are produced and sold in the same physical or digital space. Personalisation is the key driver as well as shorter supply chains. This model enables high control and optimisation of resources as material flows happen in proximity to the factory and retail floor. The case study Unto this last is an example of this type of RdM (Fig 1.). This type of RdM was identified as being the least represented by the case studies as it is the most radical model requiring the biggest transformation to our current system.

\section{$5 \quad$ Conclusions and research directions}

RdM and circular economy are relative new concepts that can potentially disrupt current models of consumer goods production and consumption. This study carried out an integrative literature review of $\mathrm{RdM}$ and circular innovation definitions, fundamental drivers, and case studies to better understand the feasibility of decentralising the consumer good sector whilst at the same time enable circular systems. The study revealed that the integration of digital intelligence can enable a distribution of knowledge, structure, ownership and different levels of customisation, offering a more connected, meaningful and durable relationships with the end user. Digital intelligence can also can allow circular business models through automated monitoring, control and optimisation of resources and material flows. The study also revealed that the use of digital intelligence has incentivised the de-centralised, re-distributed and circular models of production and consumption. However, there is not an 'ideal' example of the potential that could be achieved by integrating RdM and Circularity into the business model, and that further value creation needs to be analysed. In addition, the opportunities and challenges of $\mathrm{RdM}$ and circular innovation are not still fully explored and questions still persist. For example, could a franchise manufacturing model work? What is the scalability going to look? What are the implications for intellectual property? What will be the consumer acceptance to these disruptive models? What will be the learning capabilities needed with the use of big data? How localised vs globalised models will be managed? And, do retail ecosystems will be competing with each other?

To answer these questions, the next steps of this research will focus on further analysing with primary and secondary data the value added of four case studies representing $\mathrm{RdM}$ and circular innovation. Three of these case studies will be based on a previously analysed case studies corresponding to one of the three types of RdM identified. The fourth will be a 'pilot case study' in which an ideal vision of RdM and circular innovation will be prototyped 
To conclude, it can be said that the potential for re-distributed manufacturing and digital intelligence to enable a regenerative economy is promising, but it is essential to understand where the value is captured and delivered to provide with the significant opportunities that the decentralisation of the consumer goods sector could bring.

\section{Acknowledgements}

The EPSRC and ESRC Grant (EP/M017567/1) have funded this research as part of the Networks on Re-distributed Manufacturing. We thank our industry partners, Dragon Rouge, Cisco and Agency of Design for their time and valuable advice in the development of this feasibility study.

\section{References}

1. Su, B., Heshmati, A., Geng, Y., Yu, X.: A review of the circular economy in China: moving from rhetoric to implementation. Journal of Cleaner Production, vol. 42, pp. 215-277. (2013)

2. Ghisellini, P., Cialani, C., Ulgiati, S.: A review on circular economy: the expected transition to a balanced interplay of environmental and economic systems. Journal of Cleaner Production. In Press. (2015)

3. Moreno, M.A., Braithwaite, N., Cooper, T.: Going Beyond the Circular Economy. Care Innovation Conference Proceedings. Vienna, Austria. (2014)

4. Ellen MacArthur Foundation: A new dynamic effective business in circular economy. Ellen MacArthur Foundation. (2013)

5. Royal Society of Arts: Investigating the role of design in the circular economy. Royal Society of Arts, London. (2013)

6. Ellen MacArthur Foundation: Towards the circular economy Vol. 1: Economic and business rationale for the accelerated transition. Available from:

http://www.ellenmacarthurfoundation.org/publications/towards-the-circular-economy-vol1-an-economic-and-business-rationale-for-an-accelerated-transition Accessed on 07.01.16. (2012)

7. Ellen MacArthur Foundation: Towards the circular economy Vol. 2: Opportunities for the consumer goods sector. Available from: $\square$

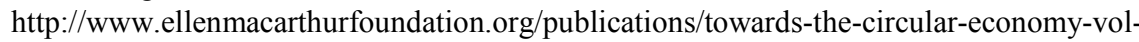
2-opportunities-for-the-consumer-goods-sector Accessed on 07.01.16 (2013)

8. Ellen MacArthur Foundation: Towards the circular economy vol.3: Accelerating the scaleup across global supply chains. Available from:

http://www.ellenmacarthurfoundation.org/publications/towards-the-circular-economy-vol3-accelerating-the-scale-up-across-global-supply-chains Accessed 07.01.15. (2014)

9. Lacy, P., and Rutqvist, J.: Waste to Wealth. The Circular Economy Advantage. Palgrave McMillan. (2015)

10. Kohtala, C.: Addressing sustainability in research on distributed production: an integrated literature review. Journal of Cleaner Production, vol.106, pp.654-668. (2014)

11. Kohtala, C., Hyysalo, S.: Anticipated environmental sustainability of personal fabrication. Journal of Cleaner Production, vol. 99, pp. 333-344. (2015)

12. Matt, D.T., Rauch, E., Dallasega, P.: Trends towards distributed manufacturing systems and modern forms for their design. ${ }^{\text {th }}$ CIRP Conference on Intelligent Computation in Manufacturing Engineering. Procedia CIRP, vol. 33, pp 185-190. (2015) 
13. Mourtzis, D., Doukas, M.: Decentralized Manufacturing Systems Review: Challenges and Outlook. In: Robust Manufacturing Control, Lecture Notes in Production Engineering, pp 355-369, (2013)

14. Foresight: The Future of Manufacturing: A new era of opportunity and challenges for the UK. The Government Office for Science, London. (2013)

15. Pearson, H., Nobel, G., Hawkins, J.: Re-Distributed Manufacturing: Workshop outputs. EPSRC. (2013)

16. Armes, R., Barbesta, A., Gora, P., Samson, C., Wright, M. \& Xu, D.: The Shift to Redistributed Manufacture. Literature Review 1. Cranfield University. Available from: http://www.recode-network.com/\#!engagement-study/c1scc Accessed 07.01.15 (2015).

17. German Trade and Investment: 'Industrie 4.0 - Smart manufacturing for the future. Available at:

http://www.gtai.de/GTAI/Content/EN/Invest/_SharedDocs/Downloads/GTAI/Brochures/I ndustries/industrie4.0-smart-manufacturing-for-the-future-en.pdf. Accessed 12.11.15. (2012).

18. Rubmann, M., Lorenz, M., Gerber, P., Waldner, M., Justus, J., Engel, P. \& Harnisch, M.: Industry 4.0 - The Future of Productivity and Growth in Manufacturing Industries. The Boston Consulting Group. (2015)

19. Livesey, F. \& Thompson, J.: Making at home owning abroad. A strategic outlook for the UK's mid sized manufacturers. Royal Society of Arts. Available at:

https://www.thersa.org/globalassets/pdfs/reports/rsa_enterprise_making_at_home_owning abroad.pdf. Accessed 12.11.15. (2013)

20. Manyika, J., Chui, M., Bisson, P., Woetzel, J., Dobbs. R., Bughin, J. \& Aharon D.: The Internet of Things mapping the value beyond the hype. Mckinsey\&Company. (2015).

21. The Economist Intelligence Unit Limited: Big Data and consumer products companies. People, processes and cultural barriers. The Economist. Available at: http://www.economistinsights.com/analysis/big-data-and-consumer-products-companies. Accessed 13.11.15. (2013)

22. Meyerson, B.: Top ten emerging technologies of 2015. World Economic Forum - Agenda. Available at: https://agenda.weforum.org/2015/03/top-10-emerging-technologies-of-20152/\#distributed-manufacturing. Accessed 13.11.15. (2015).

23. Tukker, A.: Eight types of product-service system: eight ways to sustainability? Experiences from SusProNet. Business strategy and the environment, 13(4), pp. 246-260. (2004).

24. Moch, R., Riedel, R. \& Muller, E.: Key success factors for manufacturing competitiveness and economic sustainability. Springer, Berlin Heidelberg, pp 327-332. (2014)

25. Claycomb, C., Dröge, C. \& Germain, R.: Applied customer knowledge in a manufacturing environment: flexibility for industrial firms. Industrial Marketing Management, 34 (6), pp. 629-640. (2005)

26. Faller, C. \& Feldmuller, D.: Industry 4.0 Learning Factory for regional SMEs. Published Proceedings from $5^{\text {th }}$ Conference on Learning Factories. Procedia International Academy for production Engineering, 32, pp 88-91. (2015)

27. Steffen, D., Gros, J.: Technofactory versus Mini-Plants: Potentials for a Decentralized Sustainable Furniture Production. Presented at MCPC03: the 2nd International Conference on Mass Customization and Personalization, October 6e8 2003, Munich, Germany. (2003)

28. Stahel, W.: Chapter 4: The business Angle of a Circular Economy. In: A new dynamic effective business in circular economy. Ellen MacArthur Foundation. (2013)

29. Stahel W.: Hidden innovation: R\&D in sustainable society. Science \& Public Policy, Journal of the international Science Policy Foundation 13(4). Special Issue: The Hidden Wealth. (1985) 